\title{
Valentina Fortunato, Il Telegrafo: da invenzione a simbolo di regime. Cenni storici e letterari
}

\section{Michel Arrous}

\section{(2) OpenEdition}

1 Journals

\section{Édition électronique}

URL : https://journals.openedition.org/studifrancesi/45954

DOI : $10.4000 /$ studifrancesi.45954

ISSN : 2421-5856

\section{Éditeur}

Rosenberg \& Sellier

\section{Édition imprimée}

Date de publication : 1 octobre 2007

Pagination : 454

ISSN : 0039-2944

\section{Référence électronique}

Michel Arrous, «Valentina Fortunato, II Telegrafo: da invenzione a simbolo di regime. Cenni storici e letterari », Studi Francesi [En ligne], 152 (LI | II) | 2007, mis en ligne le 30 novembre 2015, consulté le 24 novembre 2021. URL : http://journals.openedition.org/studifrancesi/45954 ; DOI : https://doi.org/ 10.4000/studifrancesi.45954

Ce document a été généré automatiquement le 24 novembre 2021.

\section{(c) 9 (i) $\Theta$}

Studi Francesi è distribuita con Licenza Creative Commons Attribuzione - Non commerciale - Non opere derivate 4.0 Internazionale. 


\title{
Valentina Fortunato, Il Telegrafo: $d a$ invenzione a simbolo di regime. Cenni storici e letterari
}

\author{
Michel Arrous
}

\section{RÉFÉRENCE}

VALENTINA FORTUNATO, Il Telegrafo: da invenzione a simbolo di regime. Cenni storici e letterari, Roma, Dipartimento di Studi Internazionali, 2006, pp. 28.

1 Comme Alphonse Foy, directeur des télégraphes sous le roi citoyen, mais sans doute pour d'autres raisons, les lecteurs de Lucien Leuwen et du Comte de Monte-Cristo voient dans l'invention de Claude Chiappe «un des ressorts administratifs les plus puissants et les plus dignes d'intérêt». Dans cet extrait de sa «tesi di laurea» (Rome III, 2004, dir. Prof. M. Di Maio) Valentina Fortunato, après un bref historique (l'invention, les débuts dès 1794, les fraudes et les aléas de la transmission des cours de la Bourse et des messages, le développement sous l'Empire, les télégraphes clandestins, etc.) retrace l'usage que fit la monarchie de Juillet de cette «machine diabolique», aux dires de la presse, et de Stendhal. On regrettera que n'aient pas été mieux utilisées les analyses et notes de Michel Crouzet dans son édition de 1982, particulièrement à propos des affaires d'Espagne et de l'idée fort répandue à l'époque selon laquelle le télégraphe faisait et défaisait les fortunes. Les gouvernements furent accusés de se réserver les dépêches et Thiers, bien à tort d'ailleurs, passa pour être le ministre du télégraphe. Autre scène historico-littéraire: les chapitres LX et LXI du Comte de Monte-Cristo où le télégraphe est l'instrument de la vengeance d'Edmond Dantès. V. Fortunato aurait pu signaler que si, dans Lucien Leuwen, Stendhal ne cesse de se référer à des événements contemporains de sa rédaction (le roman se déroule en 1834-1835), Dumas, lui, prend force libertés avec la chronologie des affaires espagnoles. Le romancier s'est surtout inspiré de l'affaire des frères Blanc, propriétaires de lignes privées, accusés en 1837 d'opérations illégales sur la Bourse de Bordeaux, entre août 1834 et aout 1836. Cette 
affaire est à l'origine de la loi du 2 mai 1837 sur le monopole. Les dernières pages sont consacrées à Hugo: de la «satire» contre la «machine qui parle» («Le Télégraphe», 1819) aux notes du voyageur qui regrette qu'elle défi- gure l'abbaye du Mont Saint-Michel - il y apprendra l'attentat d'Allibaud (1836). Le point de vue du poète évoluera sensiblement jusqu'à l'intérêt pour le "grand insecte noir» (Le Rhin) et l'enthousiasme pour le télégraphe optique et l'invention de Morse («Force des choses», Châtiments). On pourra consulter en ligne une version plus complète. 